\title{
Prospective study of management of long bone fracture by intra-medullary elastic nailing in children
}

\author{
Saijyot Raut, Deepak Jain*, Pratik Gohil, Parimal Malviya, Alfven Vieira, Tushar Agrawal
}

Department of Orthopaedics, MGM Institute of Health Sciences, Navi Mumbai, Maharashtra, India

Received: 10 November 2019

Revised: 13 January 2020

Accepted: 04 February 2020

\author{
*Correspondence: \\ Dr. Deepak Jain, \\ E-mail: deepaksjain1993@gmail.com
}

Copyright: (c) the author(s), publisher and licensee Medip Academy. This is an open-access article distributed under the terms of the Creative Commons Attribution Non-Commercial License, which permits unrestricted non-commercial use, distribution, and reproduction in any medium, provided the original work is properly cited.

\begin{abstract}
Background: The treatment of long bone fractures in children from 6 to 14 years is a challenging scenario. Titanium elastic nail (TEN) fixation was originally meant as a gold standard treatment method for femoral fractures, but was gradually applied to other long bone fractures in children, because it represents a middle path between conservative and surgical modality.

Methods: In the present study paediatric patients in the age group of 6 to 14 year with long bone fractures to be treated with TEN in the Department of Orthopaedics were admitted to MGM Hospital (Kamothe) were selected. A total of 30 patients consenting to undergo this study were subjected for treatment after screening using the inclusion and exclusion criteria.

Results: The mean age of the patients was $9.67 \pm 2.68$ years. There was male preponderance $(63.3 \%)$. In our study, RTA was observed to be the main cause of fracture (80\%) whereas $20 \%$ fractures were due to fall. In our study, $50 \%$ patients had fracture of radius ulna followed by fracture of tibia $23.3 \%$, femur $(23.3 \%)$, and humerus $(3.3 \%)$. The mean time to union was $5.30 \pm 1.06$ weeks.

Conclusions: TEN seems to be simple, biocompatible, more physiological, reliable and effective method of treatment of all long bone shaft fractures in 6 to 14 years old children. It is a rapid, safe and simple procedure with advantages of short operative time, minimal blood loss, shorter hospital stays early union, allowing early mobilization and early return to function with minimal complications.
\end{abstract}

Keywords: Paediatric fractures, TENS nail, Long bone fractures

\section{INTRODUCTION}

Children are at a high risk of injury with up to at least one of every four kids sustaining an injury annually. ${ }^{1,2}$ In which $10 \%$ to $25 \%$ of these injuries are associated with fractures, where the lifetime fracture risk is up to $40 \%$ for girls and as high as up to $64 \%$ for boys. ${ }^{3-5}$ With fractures having a substantial impact on the daily living and activity of affected children, they represent an vital topic of public health.,

In 2007, the Arbeitsgemeinschaft für Osteosynthese fragen (AO) pediatric comprehensive classification of long bone fractures (PCCF) was developed and validated keeping in mind a 3-phase concept proposed by Audigé et al. ${ }^{8,9}$ The initial two validation phases showed that the classification method based on radiographic assessment is reliable and accurate and that the PCCF system are often thought of clinically relevant by pediatric surgeons. ${ }^{10,11}$ The AO comprehensive injury automatic classifier (AO COIAC) software was developed for testing in an exceedingly clinical setting following the third and final validation section, with the aim of absolutely documenting and evaluating pediatric long bone fractures, causes, classification codes, treatments, incidence of associated complications, and outcomes. ${ }^{12}$ 
Age, sex, season, risk-taking behaviour, bone mineral density (BMD), sports conjointly violence and race or ethnicity and socioeconomic status are different risk factors for sustaining fractures in children. ${ }^{13-18}$ Overweight and obesity seem to have an increasing impact, possibly due to lower bone mass relative to body size, larger mechanical load by falls or reduced body balance and so, became major topics of interest for each treating physicians and public health. ${ }^{19-22}$

Recently diaphyseal fractures in children treated with surgical treatment is a growing trend. To some extent this reflects a additional interventionist perspective among Orthopaedic Surgeons but is also additional due to technical development, notably that of elastic stable intramedullary nail. ${ }^{23}$ Most controversial remains the treatment for children aged between 6 and 10 years. Several such patients can often be treated successfully with immediate closed reduction and casts. However, external fixator and flexible intramedullary nail fixation are being used more frequently, primarily in patients with multiple trauma. However, in older children and adolescents operative treatment should be considered to avoid complications like delayed union, mal-union, rotational deformity, re-fracture, knee stiffness, limb length discrepancy and psychosocial issues. Operative treatment has psychological, social, educational and economic advantages over conservative treatment and also has shorter hospitalization and early mobilization. Other alternatives technique mentioned above such as compression plating, external fixator, rigid Intramedullary nailing and elastic stable intramedullary nailing are being used for diaphyseal fractures in children.

With the use of external fixator, there is a high incidence of pin tract infection, re-fracture after removal of external fixator. Also, the external fixator is more uncomfortable and cumbersome for the child. ${ }^{24}$ Submuscular Compression plating needs two major operations - one for insertion and another one for the removal of the plate. ${ }^{25}$ Rigid intramedullary nails have their own pros and cons. Not only will the risk of avascular necrosis of the femoral head increase in children and adolescents, but the incidence of abnormalities in the proximal end of the femur will also increase, including coxa valga, stopping the growth of the great trochanter, thinning. of the neck of the femur damage due to the trocantere-cervical region. ${ }^{26}$

Until hard callus is made, fixation of paediatric diaphyseal fractures should produce an "internal splint" that shares loads, maintains reduction, and does not endanger the growth areas or blood supply. Results from many studies have shown that flexible intramedullary nail or titanium elastic nailing system fixation meets these requirements because it permits rapid mobilization, potentially no risk for osteonecrosis, low risk for physeal injury, and reduced risk for recurrence of fracture. Elastic stable intramedullary nailing meets the requirements of this ideal device. ${ }^{27}$

The choice of treatment may be influenced by the age of the child, the level and pattern of the fracture and to a great extent, by regional, institutional or surgeon's preferences.

Paediatric unstable fractures of long bones of lower limbs demand operative treatment to take care of alignment and preserve function. ${ }^{28}$ Many treatment choices are available for operative treatment of these fractures, however, flexible intramedullary nails have become increasingly popular in the skeletally immature population principally because of its clinical effectiveness and low risk of complications. Flexible intramedullary nailing using titanium elastic nailing system (TENS) have been used with great success in Europe for a number of decades, but it was in later half of 1990s when elastic nailing gained acceptance in North America and since then it is being extensively used.

Development of TENS has provided a simple, biocompatible, load bearing internal splint allowing early mobilization. Epiphyseal growth plate is not crossed which avoids growth disturbance and has minimal risk of complications and has thus emerged as the most popular surgical modality for management of paediatric fractures of long bones. ${ }^{29}$

An ideal fixation device for paediatric long bones fracture would be a load sharing internal splint maintaining reduction for a few weeks until callus forms. Most importantly implant should not risk the physis or the blood supply. For elastic stable intramedullary nailing titanium implants are used increasingly. The material properties of titanium confer advantages for an implant used to stabilize paediatric long bones fractures. Titanium elasticity limits the amount that the nail is permanently deformed during insertion. More importantly elasticity promotes callus formation by limiting stress shielding. Titanium also has excellent biocompatibility.

The treatment of long bone fractures in children less than 6 years and adolescents older than 16 years is comparatively straight forward. Titanium elastic nail (TEN) fixation was originally meant as a gold standard treatment method for femoral fractures, but was gradually applied to other long bone fractures in children, because it represents a middle path between conservative and surgical modality with satisfactory results and borderline complications.

Hence the present study was done at our tertiary care centre to assess the role of titanium elastic nailing system in healing of fracture of long bone in children and evaluate functional outcome and complications if any following use of titanium elastic nailing system in fracture shaft of long bones in children. 


\section{METHODS}

A hospital based observational study was done with 30 patients to study the role of titanium elastic nailing system in healing of fracture of long bone in children during August 2016 to August 2018.

In the present study paediatric patients in the age group of 6 to 14 year with long bone fractures to be treated with titanium elastic nailing in the Department of Orthopaedics were admitted to MGM hospital Kamothe were selected. A total of 30 patients consenting to undergo this study were subjected for treatment after screening using the inclusion and exclusion criteria.

Informed consent was taken from the patient's parent/guardian satisfying the inclusion criteria and all patients were included after approval from the ethics committee.

\section{Study population}

Paediatric patients in the age group of 6-14 year with long bone fractures to be treated with titanium elastic nailing in the Department of Orthopaedics at MGM Hospital (Kamothe).

\section{Inclusion criteria}

Patients aged 6 to 14 years, children with displaced diaphyseal fractures of long bones, closed or Gustilo Anderson type 1 open fracture were included in this study.

\section{Exclusion criteria}

Pathological fractures, fractures related to congenital conditions, polytrauma, old untreated fractures of shaft of long bones were excluded.

\section{Flynn scoring criteria}

Flynn scoring criteria for evaluating the results for long bone fractures in children treated with TEN. ${ }^{30}$

Table 1: Flynn scoring criteria. ${ }^{30}$

\begin{tabular}{|llll|}
\hline $\begin{array}{l}\text { Leg-length } \\
\text { discrepancy }\end{array}$ & $\begin{array}{l}\text { Excellent } \\
\text { results }\end{array}$ & $\begin{array}{l}\text { Satisfactory } \\
\text { results }\end{array}$ & $\begin{array}{l}\text { Poor } \\
\text { results }\end{array}$ \\
\hline Malalignment & $\begin{array}{l}<5 \\
\text { degrees }\end{array}$ & $\begin{array}{l}\leq 2.0 \mathrm{~cm} \\
\text { degrees }\end{array}$ & $>2.0 \mathrm{~cm}$ \\
\hline Pain & None & None & $\begin{array}{l}>10 \\
\text { degrees }\end{array}$ \\
\hline Present \\
Complication & None & $\begin{array}{l}\text { Minor and } \\
\text { resolved }\end{array}$ & $\begin{array}{l}\text { Major } \\
\text { complication } \\
\text { and lasting } \\
\text { morbidity }\end{array}$ \\
\hline
\end{tabular}

\section{Post operative care}

The patients were shifted to the respective wards after the recovery from anesthesia. Post-op IV antibiotics were continued till day three when the first dressing was done and then oral antibiotics were given for a further 1 week.

Every patient was given above knee slab, above elbow slab or Thomas' splint post operatively for 2 weeks for immobilization. Suture removal was done on day 14. Partial weight bearing in lower limb and range of motions was started after suture removal if bridging callus was seen and patient was compliant.

\section{Follow up}

Every patient was assessed clinically and radiologically at 2 weeks and 4 weeks post op and 4 weekly thereafter till 3 months. Full weight bearing and full range of motion was allowed only after sound clinical and radiological union which was generally by 6 to 8 weeks. Then follow up at 6 months, 9 months and 12 months and decision for implant removal was taken between 6 to 12 months depending upon each individual case.

\section{RESULTS}

A hospital based observational study was done with 30 patients to study the role of titanium elastic nailing system in healing of fracture of long bone in children.

\section{Distribution of patients according to age}

Majority of the patients $(36.7 \%)$ were in the age group of 6 to 8 years followed by $33.3 \%$ in the age groups of 9 to 11 years and $30 \%$ in the age group of 12 to 14 years. The mean age of the patients was $9.67 \pm 2.68$ years (Figure 1 ).

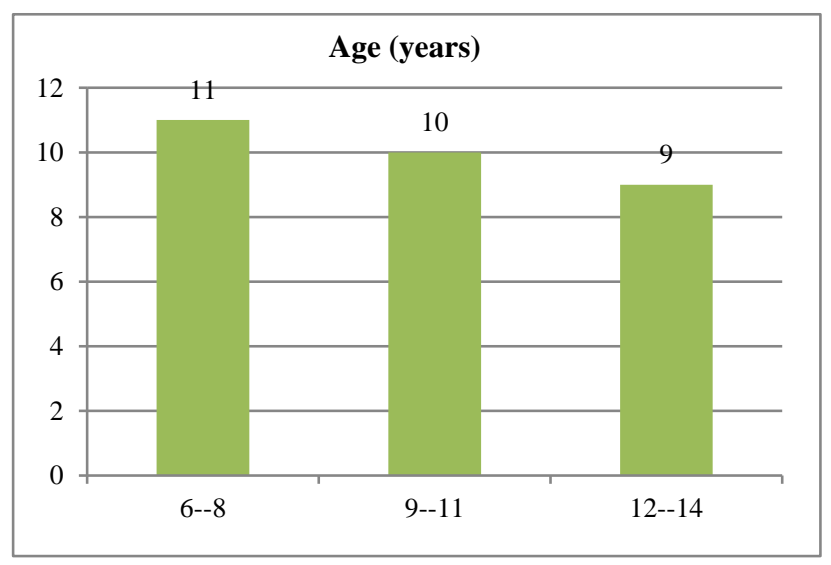

Figure 1: Distribution of patients according to age.

There was male preponderance $(63.3 \%)$ in the study while female patients constituted $36.7 \%$ of the study group (Figure 2). 


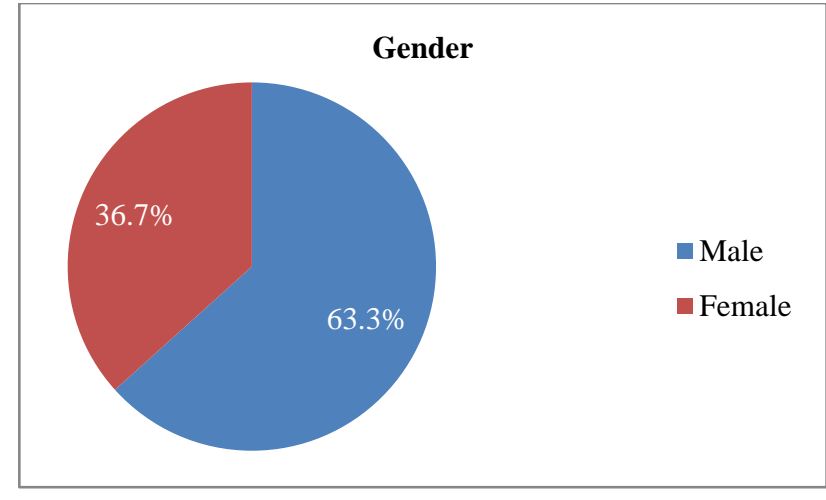

Figure 2: Distribution of patients according to gender.

In the study, there is right sided predominance compared to the left side (60\% vs. $40 \%$ ) (Figure 3).

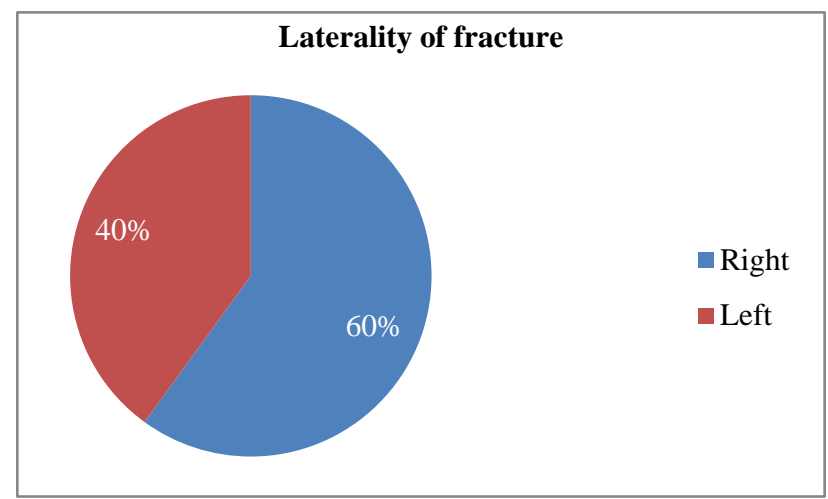

Figure 3: Distribution of patients according to laterality of fracture.

Road traffic accident was observed to be the main cause of fracture $(80 \%)$ whereas $20 \%$ fractures were due to fall (Figure 4).

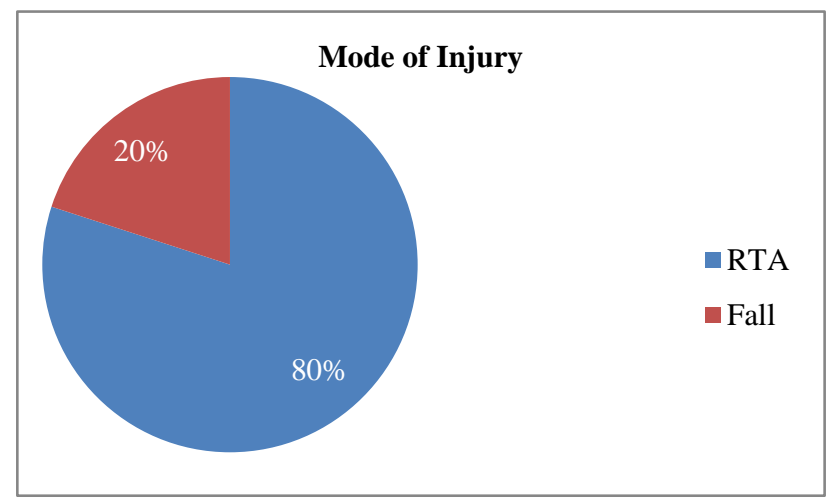

Figure 4: Distribution of patients according to mode of injury.

Majority of the patients had fractures of the middle $1 / 3^{\text {rd }}$ of the diaphysis $(73.3 \%)$ while $8(26.7 \%)$ patients had fractures of the upper $1 / 3^{\text {rd }}$ of the diaphysis (Figure 5).

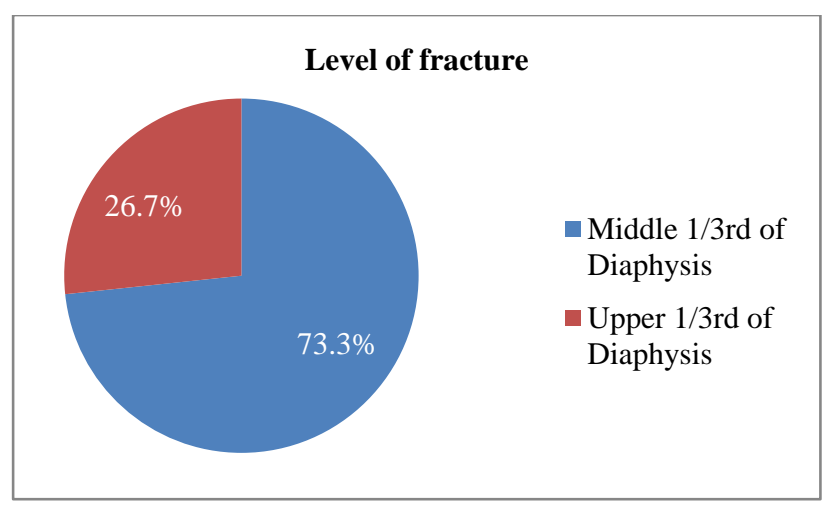

Figure 5: Distribution of patients according to level of fracture.

In our study, $15(50 \%)$ patients had fracture of radius ulna followed by fracture of tibia $(23.3 \%)$, femur $(23.3 \%)$, and humerus (3.3\%) (Figure 6).

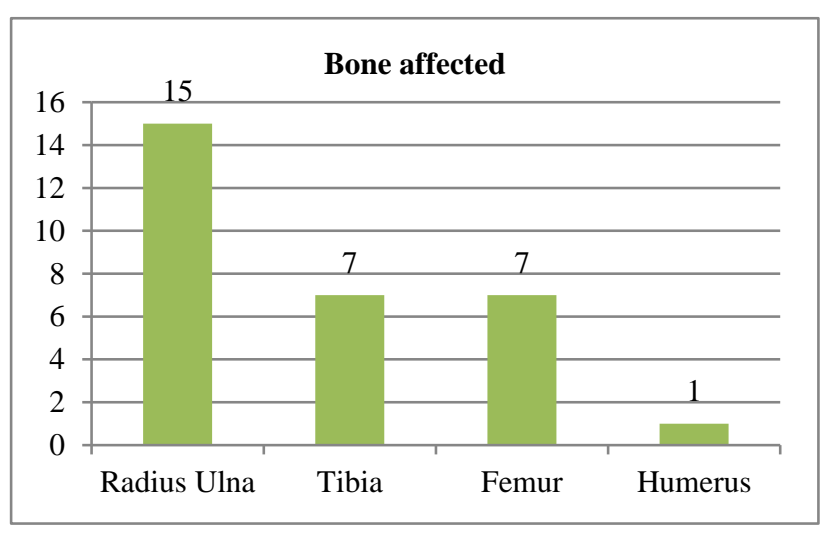

Figure 6: Distribution of patients according to bone affected.

The injury to surgery interval for $10(33.3 \%)$ patients was $<24$ hours, while it was 1 to 2 days for $14(46.7 \%)$ patients. $6(20 \%)$ patients had to wait for $>2$ to 3 days before getting operated (Figure 7).

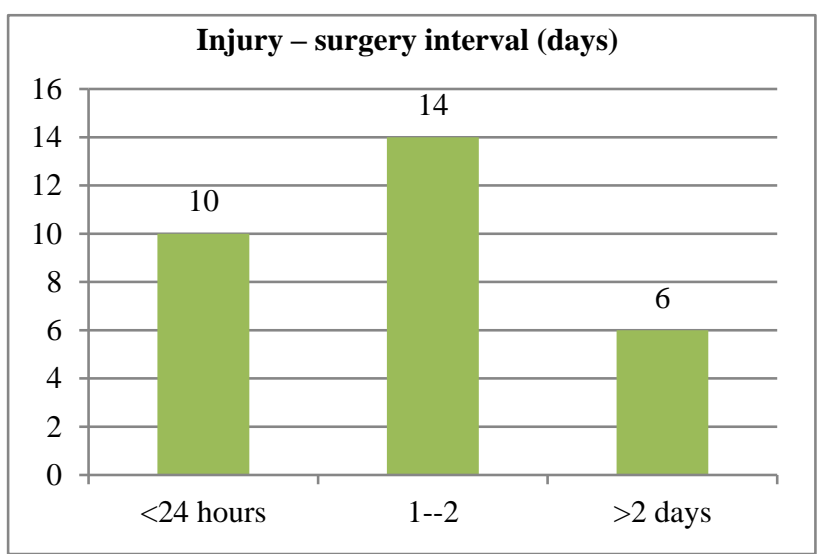

Figure 7: Injury - surgery interval of patients. 
$5(16.7 \%)$ and $12(40 \%)$ patients had operative time of 30 to 45 minutes and 45 to 60 minutes respectively while 7 $(23.3 \%)$ and $6(20 \%)$ patients had operative time of 60 to 75 minutes and 75 to 90 minutes respectively. The mean operative time was $58.83 \pm 17.75$ mins (Figure 8 ).

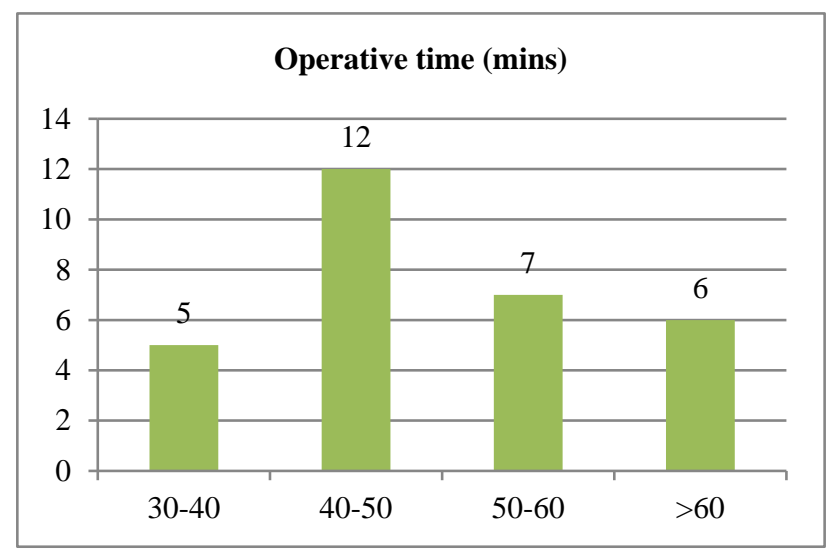

Figure 8: Distribution of patients according to operative time.

Majority of the patients $(83.3 \%)$ were admitted in the hospital for $\leq 7$ days while $5(16.7 \%)$ patients were admitted in the hospital for 7 to 14 days. The mean hospital stay was 5.70 \pm 2.64 days (Figure 9).

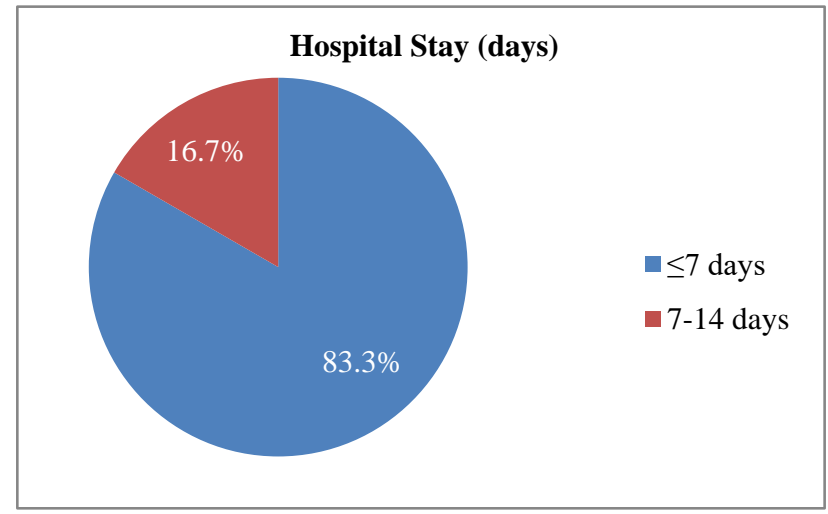

Figure 9: Distribution of patients according to hospital stay.

Majority of the patients (90\%) had full union by 4 to 6 weeks post operatively while $2(6.7 \%)$ and 1 (3.3\%) patients had full union in $\leq 4$ weeks and 6-8 weeks respectively. The mean time to union was $5.30 \pm 1.06$ weeks (Figure 10).

$3(10 \%)$ patients reported skin irritation while $2(6.7 \%)$ and $1(3.3 \%)$ patient had superficial infection and limb length difference $>1 \mathrm{~cm}$ respectively (Figure 11).

Outcome was evaluated as per Flynn scoring criteria. 25 $(83.3 \%)$ patients had excellent results while $5(16.7 \%)$ patients had satisfactory results. There were no poor results (Figure 12).

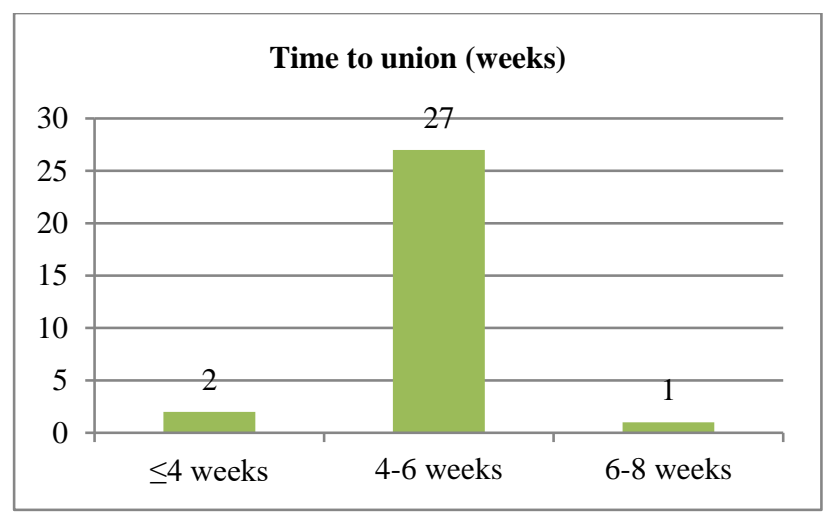

Figure 10: Distribution of patients according to time to union.

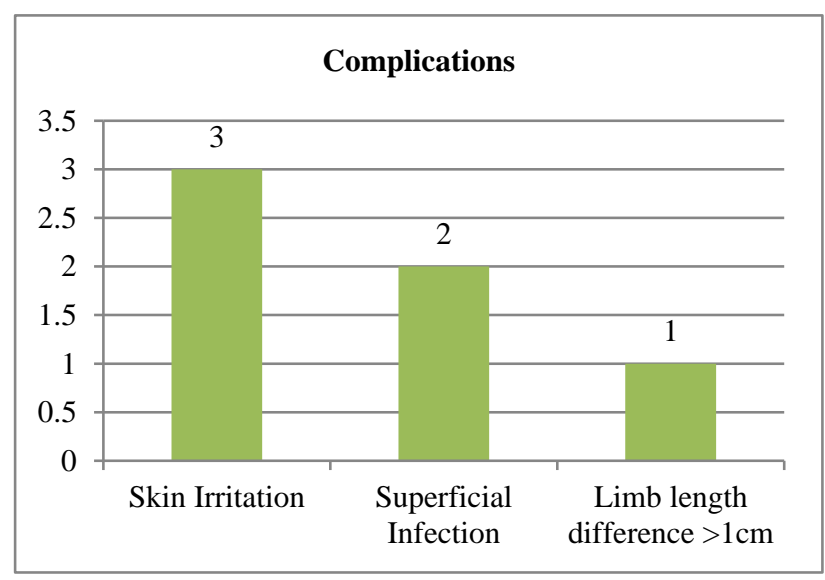

Figure 11: Distribution of patients according to complications.

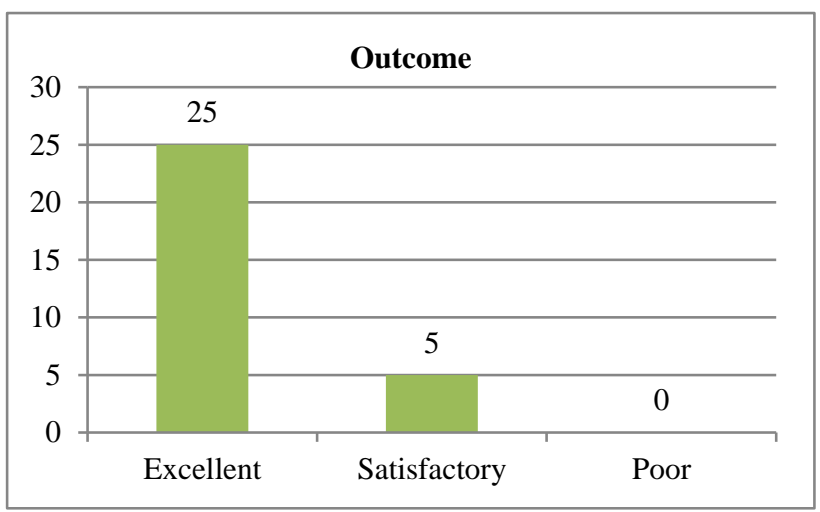

Figure 12: Distribution of patients according to outcome.

\section{DISCUSSION}

A hospital based observational study was done with 30 patients to study the role of titanium elastic nailing system in healing of fracture of long bone in children.

The majority of emergency cases in most trauma centres are fractures of long bones. The majority of long bones shaft fractures in children can be treated with closed 
reduction and casting, but sometimes surgical stabilization is required.

Historically, external fixation has been the treatment of choice; however, risks include pin-track infections, nonunion, and refracture. Reamed locked intramedullary nails, while shown to be effective in the skeletally mature, pose unnecessary risk to the long bones physis, and have limited indications in those children with growth remaining. For femoral fractures, the risk of avascular necrosis may increase if fossa piriformis is used as an entry point. ${ }^{28}$

The elastic stable intramedullary nail is now commonly used for the treatment of pediatric long bones fractures and their use has minimised the surgical scarring previously caused by open reduction and plating. This method achieve biomechanical stability from the divergent " $C$ "' configuration which creates six points of fixation and allows the construct to act as an internal splint. ${ }^{28}$ The elastic stable intramedullary nail provide stable and elastic fixation, allowing for controlled motion at the fracture site which results in healing by external callus.

Several studies have demonstrated the safety and efficacy of this technique. ${ }^{29}$ The elastic stable intramedullary nail is not without the possibility of complication. Complications usually are based on mistakes concerning the indication or technical errors. The most common reported complications associated with these techniques include infection, overgrowth, entry site skin irritation and re-fracture.

In the present study, majority of the patients $(36.7 \%)$ were in the age group of 6 to 8 years followed by $33.3 \%$ in the age groups of 9 to 11 years and $30 \%$ in the age group of 12 to 14 years. The mean age of the patients was $9.67 \pm 2.68$ years. There was male preponderance $(63.3 \%)$ in the study while female patients constituted $36.7 \%$ of the study group.

\section{CONCLUSION}

TEN seems to be more physiological and effective method of treatment of all long bone shaft fractures in 614 years old children. It is a rapid, safe and simple procedure with advantages of early union, early mobilization and early return to function with minimal complications. TEN is a simple, biocompatible, reliable and effective method for management of paediatric fractures of long bones of lower extremity with short operative time, minimal blood loss, shorter hospital stay, allowing rapid mobilization and minimal complications.

Funding: No funding sources Conflict of interest: None declared

Ethical approval: The study was approved by the institutional ethics committee

\section{REFERENCES}

1. Scheidt PC, Harel Y, Trumble AC, Jones DH, Overpeck MD, Bijur PE. The epidemiology of nonfatal injuries among US children and youth. Am J Public Health. 1995;85(7):932-8.

2. Walsh SS, Jarvis SN, Towner EM, Aynsley-Green A. Annual incidence of unintentional injury among 54,000 children. Inj Prev. 1996;2(1):16-20.

3. Landin LA. Epidemiology of children's fractures. J Pediatr Orthop B. 1997;6(2):79-83.

4. Cooper C, Dennison EM, Leufkens HG, Bishop N, van Staa TP. Epidemiology of childhood fractures in Britain: a study using the general practice research database. J Bone Miner Res. 2004;19(12):1976-81.

5. Rivara FP, Calonge N, Thompson RS. Populationbased study of unintentional injury incidence and impact during childhood. Am J Public Health. 1989;79(8):990-4.

6. Kopjar B, Wickizer TM. Fractures among children: incidence and impact on daily activities. Inj Prev. 1998;4(3):194-7.

7. Valerio G, Galle F, Mancusi C, Di Onofrio V, Colapietro M, Guida P, et al. Pattern of fractures across pediatric age groups: analysis of individual and lifestyle factors. BMC Public Health. 2010;10:656-710.

8. Slongo TF, Audige L, Group AOPC. Fracture and dislocation classification compendium for children: the AO pediatric comprehensive classification of long bone fractures (PCCF). J Orthop Trauma. 2007;21(10 Suppl):S135-60.

9. Audige L, Bhandari M, Hanson B, Kellam J. A concept for the validation of fracture classifications. J Orthop Trauma. 2005;19(6):401-6.

10. Slongo T, Audige L, Clavert JM, Lutz N, Frick S, Hunter J. The AO comprehensive classification of pediatric long-bone fractures: a web-based multicenter agreement study. J Pediatr Orthop. 2007;27(2):171-80.

11. Slongo T, Audige L, Schlickewei W Clavert JM, Hunter J, International Association for Pediatric Traumatology. Development and validation of the AO pediatric comprehensive classification of long bone fractures by the Pediatric Expert Group of the AO Foundation in collaboration with AO Clinical Investigation and Documentation and the International Association for Pediatric Traumatology. J Pediatr Orthop. 2006;26(1):43-9.

12. AO comprehensive injury automatic classifier (AOCOIAC). Available at: https://www.aofoundation.org/Structure/resource/AO-OTA-Fracture-Dislocation-Classification/comprehensive-injury-automatic-classifier/Pages/Comprehensive-Injury-Automatic-Classifier.aspx. Accessed on 3 November 2019.

13. Mathison DJ, Agrawal D. An update on the epidemiology of pediatric fractures. Pediatr Emerg Care. 2010;26(8):594-603. 
14. Brudvik C, Hove LM. Childhood fractures in Bergen, Norway: identifying high-risk groups and activities. J Pediatr Orthop. 2003;23(5):629-34.

15. Caine D, Caine C, Maffulli N. Incidence and distribution of pediatric sport-related injuries. Clin J Sport Med. 2006;16(6):500-13.

16. Hedstrom EM, Svensson O, Bergstrom U, Michno P. Epidemiology of fractures in children and adolescents. Acta Orthop. 2010;81(1):148-53.

17. Rennie L, Court-Brown CM, Mok JY, Beattie TF. The epidemiology of fractures in children. Injury. 2007;38(8):913-22.

18. Schalamon J, Dampf S, Singer G, Ainoedhofer H, Petnehazy T, Hoellwarth ME, et al. Evaluation of fractures in children and adolescents in a Level I Trauma Center in Austria. J Trauma. 2011;71(2):E19-25.

19. Dimitri P, Bishop N, Walsh JS, Eastell R. Obesity is a risk factor for fracture in children but is protective against fracture in adults:a paradox. Bone. 2012;50(2):457-66.

20. Dimitri P, Wales JK, Bishop N. Fat and bone in children:differential effects of obesity on bone size and mass according to fracture history. J Bone Miner Res. 2010;25(3):527-36.

21. Goulding A, Jones IE, Taylor RW, Piggot JM, Taylor D. Dynamic and static tests of balance and postural sway in boys:effects of previous wrist bone fractures and high adiposity. Gait Posture. 2003; 17(2):136-41.

22. de Onis M, Blossner M, Borghi E. Global prevalence and trends of overweight and obesity among preschool children. Am J Clin Nutr. 2010;92(5):1257-64.

23. Barry M, Paterson JMH. Flexible intramedullary nails for fractures in children, J Bone Joint Surg Br 2004;86:947-53.
24. Linhart WE, Roposch A. Elastic stable intramedullary nailing for unstable femoral fractures in children:preliminary results of a new method. $\mathrm{J}$ Trauma. 1999;47(2):372-8.

25. Gonzalez HP, Burgos FJ, Rapariz JM. Intramedullary nailing of the femur in children, Effects on its proximal end. J Bone Joint Surg Br. 1995;77(2):262-6.

26. Thometz JG, Lamdan R. Osteonecrosis of the Femoral Head after Intramedullary Nailing of a Fracture of the Femoral Shaft in an Adolescent. J Bone Joint Surg Am. 1995;77(9):1423-6.

27. Flynn JM, Hresko T, Reynolds RA, Blasier RD, Davidson R, Kasser J. Titanium elastic nails for pediatric femur fractures:a multicenter study of early results with analysis of complications. J Pediatr Orthop. 2001;21(1):4-8.

28. Sankar WN, Jones KJ, Horn BD, Wells L. Titanium elastic nails for pediatric shaft fractures. J Child Orthop. 2007;1(5):281-6.

29. Flynn JM, Hresko T, Reynolds RA, Blasier RD, Davidson R, Kasser J. Titanium elastic nails for paediatric femur fractures:A multi-center study of early results with analysis of complications. J Pediatr Orthop. 2001;21:4-8.

30. Flynn JC, Mathews JG, Benoit RL. Blind pinning of displaced supracondylar Fractures of the humerus in children :Sixteen years experience with long term follow up. J Bone Joint Surg Am. 1974;56:263-72.

Cite this article as: Raut $\mathrm{S}$, Jain D, Gohil $\mathrm{P}$, Malviya P, Vieira A, Agrawal T. Prospective study of management of long bone fracture by intra-medullary elastic nailing in children. Int J Res Orthop 2020;6:353-9. 